\title{
Influence of orientation and temperature on the fatigue crack growth of directionally solidification superalloys DZ125
}

\author{
Yi Shi ${ }^{1,{ }^{*}}$, Xiaoguang Yang ${ }^{1}$, Didi Yang ${ }^{1}$, Guolei Miao ${ }^{2}$ and Duoqi Shi $^{1}$ \\ ${ }^{1}$ School of Energy and Power Engineering, Beihang University, 100191 Beijing, China \\ ${ }^{2}$ Chengdu Holy Industry \& Commerce Corp.LTD, 611936, Sichuan Province, China
}

\begin{abstract}
The influence of orientation and temperature on the fatigue crack growth of a directionally solidification superalloys named DZ125 were investigated in this study. The specimens were designed based on ASTM E647 standard and the compliance method was employed to monitor the crack growth. Tests were conducted at room temperature, $760^{\circ} \mathrm{C}$ and $850^{\circ} \mathrm{C}$ respectively. The longitudinal and transverse orientation were both studied in this tests. Results show that the orientation dependence is weak at elevated temperature compared with that at room temperature. However, the temperature influences the fatigue crack growth rate significantly and the largest difference can be an order of magnitude on the da/dN- $\Delta \mathrm{K}$ graph. But the reduction in higher $\Delta \mathrm{K}$ area of elevated temperature can still be observed. Potential reasons and hypothesis were explained in this paper. In addition, the crack growth mode appears to transfer from type I with the increase of temperature which also reflects the influence of temperature.
\end{abstract}

\section{Introduction}

DZ125 is a Chinese made nickel based directionally solidification superalloys, which is similar to the Rene'125 in USA. Due to its good resistance to creep and excellent strength at elevated temperature, it is applied for blades and vanes of advanced aero-engine ${ }^{[1]}$. However, the working condition of turbine blades is so harsh that it is close to the materials' capability limit. To ensure the safety of operation, understanding the behavior of fatigue crack growth at elevated temperature is important for design and maintenance. Many previous studies focused on DZ125's behavior of low cycle fatigue life at elevated temperature ${ }^{[2-3]}, \operatorname{TMF}^{[4]}$, and environment and coating influence ${ }^{[5-6]}$ by conducting experiments on smooth cylinder specimen, while less efforts are put on the fatigue crack growth behavior of DZ125. Other directionally solidification material like IN738, GTD-111's fatigue crack growth behavior were studied.

This study aims at investigating the influence of orientation and temperature on the fatigue crack growth behaviour of DZ125. The fatigue crack growth rates were obtained by conducting experiments and the crack growth path was also compared to analyze the temperature and orientation effects.

\section{Experiment}

\subsection{Material and specimen}

The material was subjected to the following heat treatment: $1180^{\circ} \mathrm{C} / 2 \mathrm{~h} \rightarrow 1230{ }^{\circ} \mathrm{C} / 3 \mathrm{~h}, \mathrm{AC}+1100{ }^{\circ} \mathrm{C} / 4 \mathrm{~h}$, $\mathrm{AC}+870 \circ \mathrm{C} / 20 \mathrm{~h}$, and $\mathrm{AC}$ ( $\mathrm{AC}$ : air cooling) before machined. The nominal chemical composition is presented in Table. 1 and mechanical properties at different temperature are listed in Table. 2.

All the test specimens were machined from three pads whose dimension was $2000 \times 60 \times 20 \mathrm{~mm}$. The directional solidification direction was shown in Fig. 1. The compact tension (CT) specimens, shown in Fig. 2 were designed based on the ASTM E647 standard ${ }^{[7]}$, with $50 \mathrm{~mm}$ wide and $10 \mathrm{~mm}$ thick. The notch length of the CT specimen is $\mathrm{a}_{0}=8 \mathrm{~mm}$. They specimens are divided into two groups, $\mathrm{T}$ and $\mathrm{L}$. For the loading direction is parallel to the directionally solidification direction, these specimens are denoted as L-CT. While for the loading direction is perpendicular to the directionally solidification direction, such specimens are denoted as T-CT, as shown in Fig. 1.In addition, to accommodate the extensometer, the knife edge at the side of CT specimen for elevated temperature is different from that of a room temperature specimen.

\subsection{Test method}

In this study, the compliance method was applied to monitor the length of crack according to ASTM E647.

*Corresponding author: shiyi_sepe@buaa.edu.cn 
The definition of compliance, $c=\delta / \mathrm{P}$, is the instantaneous ratio between displacement and load ${ }^{[8]}$, which is also the reciprocal of the stiffness D. Also, the compliance would remain constant until the crack has new advance. The compliance value increases with the crack growth, which also indicates the degraded resistance to the external load. At the premise of linear condition, such relationship can be analytically expressed in a dimensionless value, $(\mathrm{EvB} / \mathrm{P}, \mathrm{E}$ is the elastic modulus, $\mathrm{V}$ is the displacement between measurement points, $\mathrm{B}$ is the specimen thickness and $\mathrm{P}$ is force) and later is correlated to the crack length, which is similar to the potential drop method ${ }^{[9]}$.The theoretical compliance expression for CT specimen is given in the E647 standard, see equation (1)

$$
\mathrm{a} / W=N_{0}+N_{1} U+N_{2} U^{2}+N_{3} U^{3}+N_{4} U^{4}+N_{5} U^{5}
$$

Where: $\mathrm{U}=1 /\left[A^{\frac{1}{2}}+1\right] ; \mathrm{A}=\varepsilon E B W / P ; N_{0}=1.0033 ; N_{1}=-2.35 ; N_{2}=1.3694 ; N_{3}=-15.294 ; N_{4}=63.182 ; N_{5}=$ -74.42 , for $0.2<a / W<0.95$

Table. 1. Nominal chemical compositions of DZ125 (wt. \%)

\begin{tabular}{|c|c|c|c|c|c|c|c|c|c|c|}
\hline $\mathrm{Ni}$ & $\mathrm{C}$ & $\mathrm{Cr}$ & $\mathrm{Co}$ & $\mathrm{W}$ & $\mathrm{Mo}$ & $\mathrm{Al}$ & $\mathrm{Ti}$ & $\mathrm{Ta}$ & $\mathrm{B}$ & $\mathrm{Hf}$ \\
\hline $\mathrm{Bal}$ & 0.096 & 8.77 & 9.88 & 7.29 & 2.00 & 5.13 & 1.03 & 3.70 & 0.015 & 1.42 \\
\hline
\end{tabular}

Table. 2. Material tensile properties

\begin{tabular}{|c|c|c|c|c|c|c|c|c|}
\hline Orientation & \multicolumn{4}{|c|}{ Longitude } & \multicolumn{4}{c|}{ Transverse } \\
\hline Temperature( $^{\circ} \mathbf{C}$ ) & 20 & 760 & 850 & 900 & 20 & 760 & 850 & 900 \\
\hline Young's modulus (GPa) $^{\mid}$ & 125.5 & 99.5 & 91.0 & 82.0 & 152.5 & 115.5 & 117.0 & 110.0 \\
\hline Tensile strength (MPa) & 1220 & 1200 & 1040 & 860 & 990 & 940 & 915 & 810 \\
\hline $\mathbf{0 . 2 \%}$ offset yield strength (MPa) & 915 & 960 & 825 & 635 & 815 & 730 & 760 & 625 \\
\hline Elongation (\%) & 11.0 & 13.0 & 16.0 & 19.0 & 13.0 & 9.7 & 9.0 & 8.7 \\
\hline Reduction in area (\%) & 12.5 & 20.0 & 21.0 & 26.0 & 20.0 & 26.0 & 24.0 & 23.0 \\
\hline
\end{tabular}

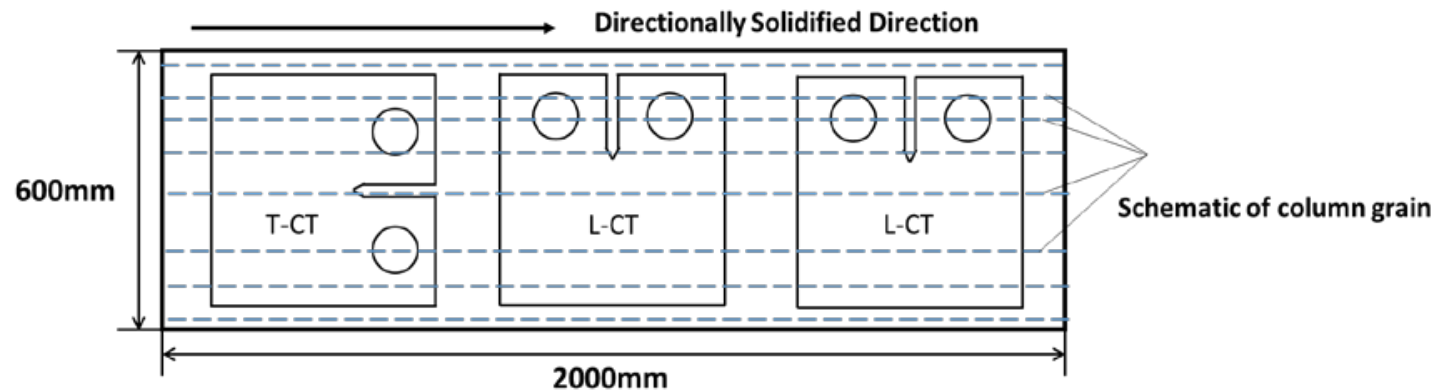

Fig. 1. The schematic of spemiens cut from a tab

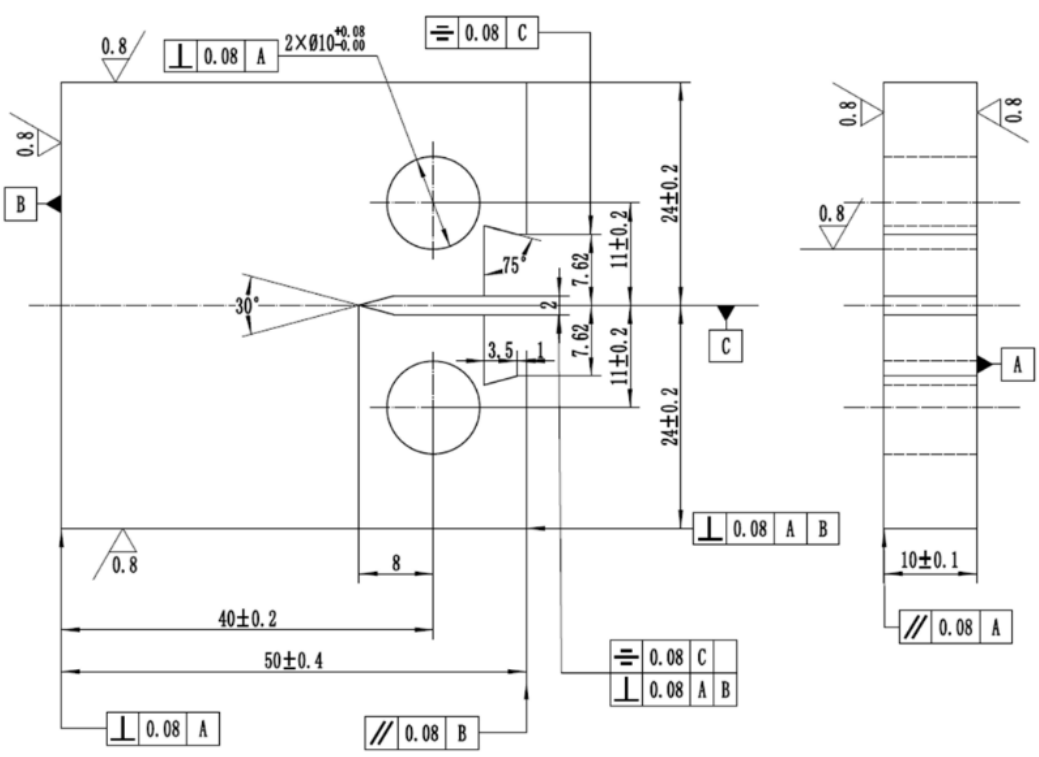


Fig. 2. The geometry of the compact tension specimen

The optical method was not utilized in this study due to the extremely high temperature. According to the physical law: anything will emit various radiation at any temperature. When the surface temperature is below 500 ${ }^{\circ} \mathrm{C}$, it mainly emits infrared light with longer wave length. Generally, the sensor of camera is not sensitive to the long wave length. Therefore, there will be no influence on the brightness of the captured images. However, with the temperature increases, the corresponding wavelength shifts to shorter area which falls into the sensitive area of the sensor. Thus, the image will be too bright to observe and measure the crack length ${ }^{[10]}$.

\subsection{Experimental Procedure}

All the fatigue crack growth tests were conducted on the MTS 370 servo-hydraulic system. The load was monitored by the system load cell. Prior to the fatigue crack growth test, all specimens were pre-cracked for $1 \mathrm{~mm}$ at room temperature to ensure the shape of crack inside meets the corresponding requirement. Then the knife edge was machined to accommodate the extensometer. The gage whose length was $15.2 \mathrm{~mm}$ and the diameter was $5 \mathrm{~mm}$ was assembly at the knife edge of the specimen. This is designed to extend to the furnace, shown in Fig. 3. To ensure the accuracy of

$$
\Delta \mathrm{K}=\frac{\Delta P}{B \sqrt{W}} \frac{(2+\alpha)}{(1-\alpha)^{3 / 2}}\left(0.886+4.64 \alpha-13.32 \alpha^{2}+14.72 \alpha^{3}-5.6 \alpha^{4}\right)
$$

Table. 3. Test conditions for specimens

\begin{tabular}{|c|c|c|c|c|c|}
\hline $\begin{array}{c}\text { Test } \\
\text { Specimens }\end{array}$ & $\begin{array}{c}\text { Temperature } \\
{ }^{\circ} \mathrm{C}\end{array}$ & $\begin{array}{c}\text { Maximum } \\
\text { Loading } \\
\text { kN }\end{array}$ & $\begin{array}{l}\text { Loading } \\
\text { Ratio }\end{array}$ & Frequency & Ending cycles \\
\hline L1 & RT & 8.6 & \multirow{8}{*}{0.1} & \multirow{8}{*}{$10 \mathrm{~Hz}$} & 163017 cycles \\
\hline $\mathrm{T} 1$ & RT & 8.6 & & & 341389 cycles \\
\hline L4 & 850 & 8.6 & & & 53517 cycles \\
\hline L5 & 850 & 8.6 & & & $\begin{array}{c}\text { Fail, } 618600 \text { cycles } \\
\text { No Propagation }\end{array}$ \\
\hline L6 & 850 & 9.4 & & & $\begin{array}{c}\text { Fail, } 20503 \text { cycles, } \\
\text { No Propagation }\end{array}$ \\
\hline L9 & 760 & 9.4 & & & 32919 cycles \\
\hline T3 & 760 & 9.4 & & & 31460 cycles \\
\hline T8 & 850 & 10.0 & & & 19433 cycles \\
\hline
\end{tabular}




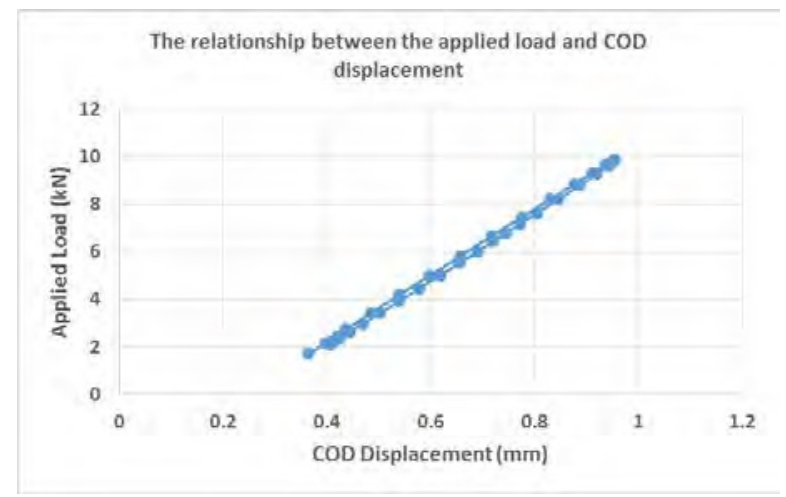

Fig. 3. The relationship between the applied load and COD displacement

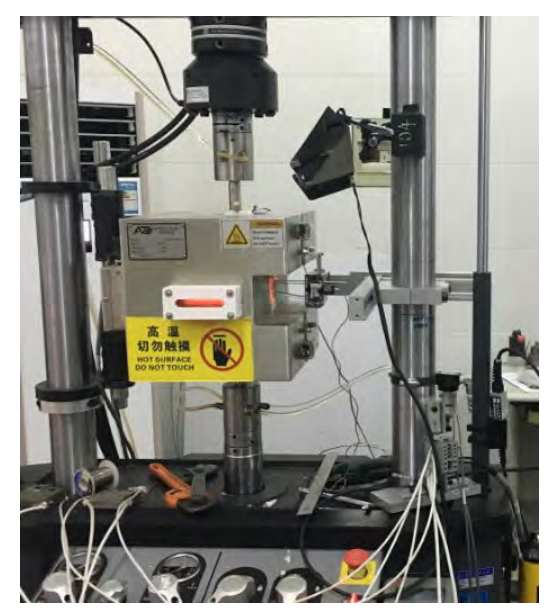

Fig. 4. The setup of the elevated temperature

\section{Result and discussion}

\subsection{The fatigue crack growth rates}

The overall test results are plotted in the Paris regime, shown in Fig. 5. The influence of temperature is obvious, especially for the difference between elevated temperature and room temperature. Meanwhile, the fatigue crack growth (FCG) rate curves were also correlated according to the Paris Law, the result are shown in Table. 4. The correlation coefficients have an average of 0.97 , which means the curve fits the Paris Law well.

$$
\frac{d a}{d N}=C(\Delta K)^{m}
$$

Table. 4 Material constant and correlation coefficient for various temperature and orientation

\begin{tabular}{|c|c|c|c|c|}
\hline Temperature & Orientation & $\mathbf{C}$ & $\mathbf{~ m}$ & $\mathbf{R}$ \\
\hline \multirow{2}{*}{$\begin{array}{c}\text { Room } \\
\text { temperature }\end{array}$} & $\mathbf{L}$ & $1.63 \times 10^{-11}$ & 4.74 & 0.99 \\
\cline { 2 - 5 } & $\mathbf{T}$ & $5.65 \times 10^{-11}$ & 4.34 & 0.99 \\
\hline \multirow{2}{*}{$\mathbf{7 6 0}^{\circ} \mathbf{C}$} & $\mathbf{L}$ & $3.86 \times 10^{-10}$ & 4.09 & 0.97 \\
\cline { 2 - 5 } & $\mathbf{T}$ & $2.17 \times 10^{-8}$ & 2.90 & 0.97 \\
\hline \multirow{2}{*}{$\mathbf{8 5 0}^{\circ} \mathbf{C}$} & $\mathbf{L}$ & $3.35 \times 10^{-11}$ & 5.05 & 0.98 \\
\cline { 2 - 5 } & $\mathbf{T}$ & $3.79 \times 10^{-9}$ & 3.57 & 0.99 \\
\hline
\end{tabular}

The change of coefficient $\mathrm{C}$ and $\mathrm{m}$ with the temperature is shown in Fig. 6. Both orientation exhibits the same trend in coefficient $\mathrm{C}$ and $\mathrm{m}$ respectively, but the trends between two coefficients are converse. Coefficient $\mathrm{C}$ for orientation $\mathrm{T}$ first increased with the growth of temperature. After peaking at the $760^{\circ} \mathrm{C}$, it dropped. Whereas, coefficient $\mathrm{m}$ for orientation $\mathrm{T}$ first decreased and then reached its bottom at $760^{\circ} \mathrm{C}$ before increased at $850^{\circ} \mathrm{C}$. In addition, the coefficient $\mathrm{C}$ for orientation $\mathrm{T}$ is always higher than that of $\mathrm{L}$, while the coefficient $\mathrm{m}$ for orientation $\mathrm{T}$ is much lower than $\mathrm{L}$. It seems to be that the coefficient $\mathrm{m}$ and $\mathrm{C}$ are independent of the temperature for both directions. 


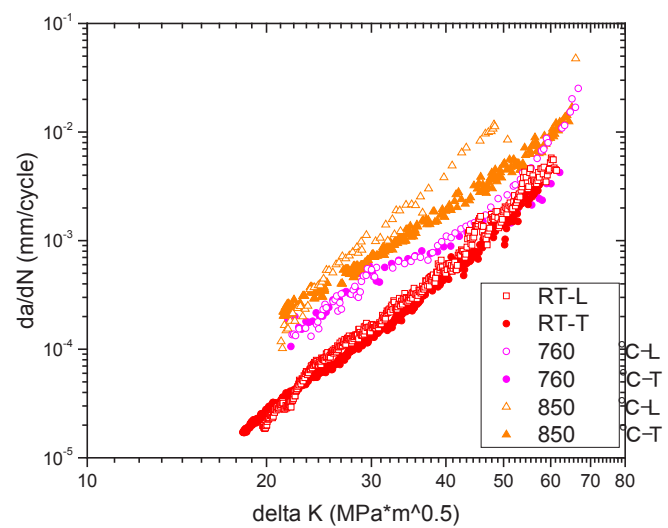

Fig. 5. The da/dN- $\Delta \mathrm{K}$ curve of six specimens
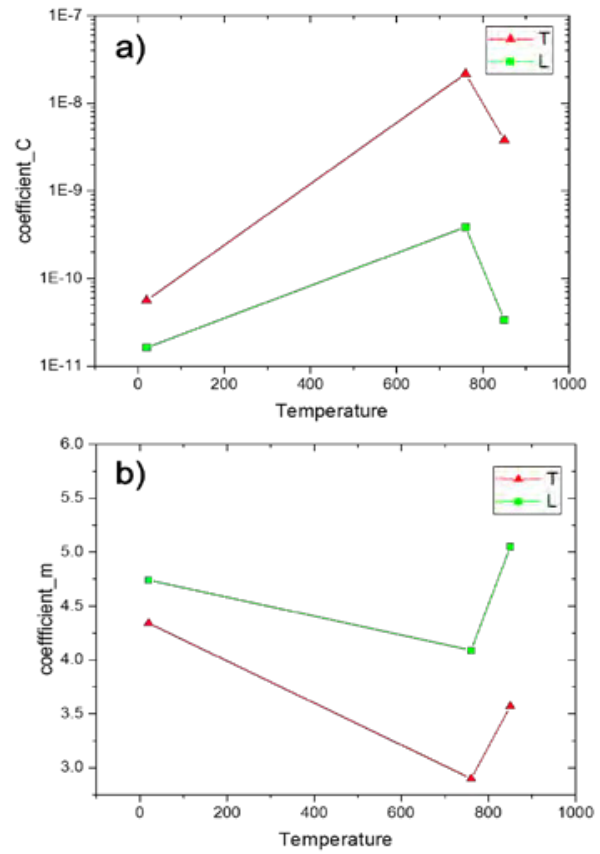

Fig. 6. The relationship between temperature and coefficients, a) $\mathrm{C}, \mathrm{b}) \mathrm{m}$

Fig. 7 shows the comparison between parts of the test results and handbook data ${ }^{[11]}$. The hollow points represent the data collected from the handbook. The test points are almost consistent with the presented data in the medium and high $\Delta \mathrm{K}$ area, which also means that the result obtained by compliance method is also confident.

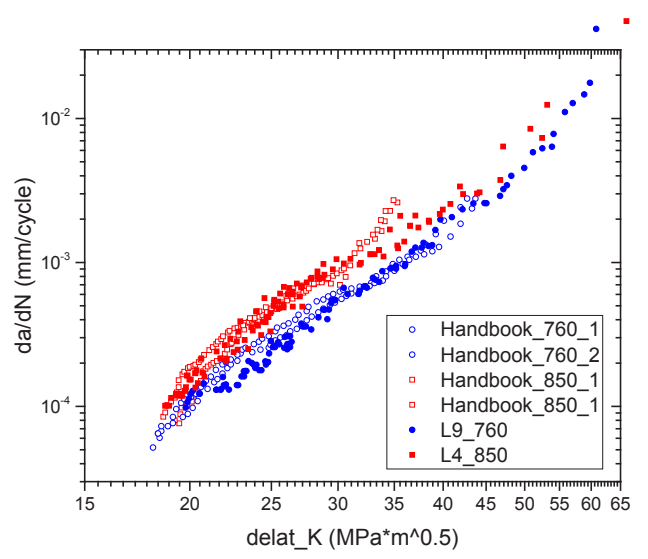

Fig. 7. The comparsion between the curve from test and handbook

\subsection{Influence of orientation on FCG rates}

Fig. 8 shows the crack growth behavior for T \& L orientation at three different temperatures. At the room temperature, the specimen of L exhibited higher FCG rate than that of $\mathrm{T}$ through all stages of $\Delta \mathrm{K}$, and more specifically the difference seems to be 3-5times at the medium $\Delta \mathrm{K}$ level. When it comes to the elevated temperature, there is no such significant difference at lower and medium $\Delta \mathrm{K}$ level between the $\mathrm{L}$ and $\mathrm{T}$ orientation. However, for $760^{\circ} \mathrm{C}$, in higher $\Delta \mathrm{K}$ level, the FCG rates between orientation $\mathrm{L}$ and $\mathrm{T}$ separate obviously. The FCG rate of L is much higher than that of $\mathrm{T}$ at the same stress intensity factor, which is not observed in other temperature. The orientation seems to less influence the FCG rates with the increase of temperature. For $850^{\circ} \mathrm{C}$, the gap between red curve and blue curve in higher $\Delta \mathrm{K}$ level is reduced compared with $760{ }^{\circ} \mathrm{C}$. In general, the $\mathrm{FCG}$ rates of $\mathrm{L}$ orientation is higher than $\mathrm{T}$ at the three test temperature. However the difference becomes slighter with the increase of temperature, except the obvious difference in higher $\Delta \mathrm{K}$ level at $760^{\circ} \mathrm{C}$. In other words, the influence of orientation of FCG rates is limited at elevated temperature. This is also consistent with other studies: Shi ${ }^{[12]}$ studied the directionally solidification nickel based superalloys PW1484 at high temperature and pointed that the effect of orientation on the crack propagation is very small. Yoon ${ }^{[13]}$ also founded that for the GTD-111 the orientation dependence was marginal at the temperature of 649,761 or $871{ }^{\circ} \mathrm{C}$.Although Yoon did not point out the orientation influence at room temperature, an obvious difference can be found in the corresponding graphs. 


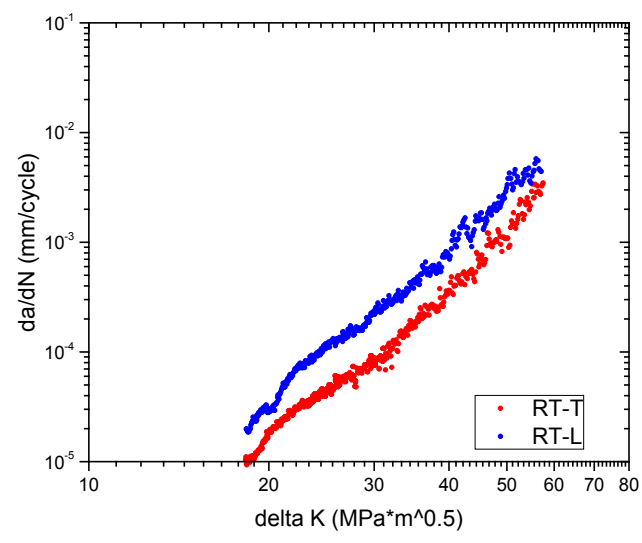

(a) room temperature

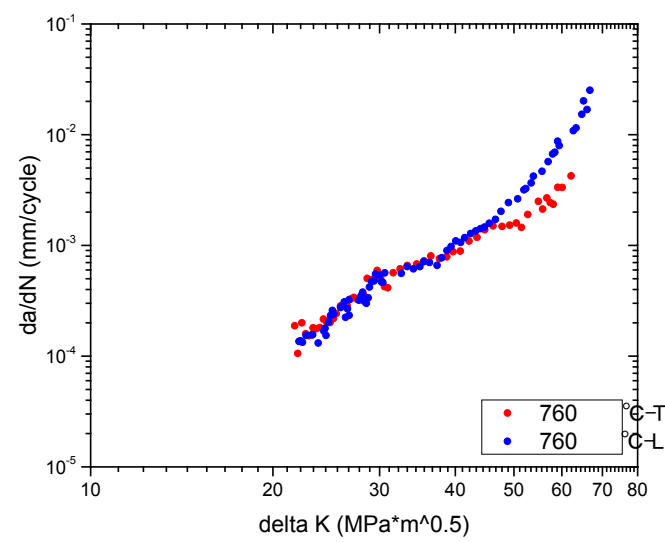

(b) $760^{\circ} \mathrm{C}$

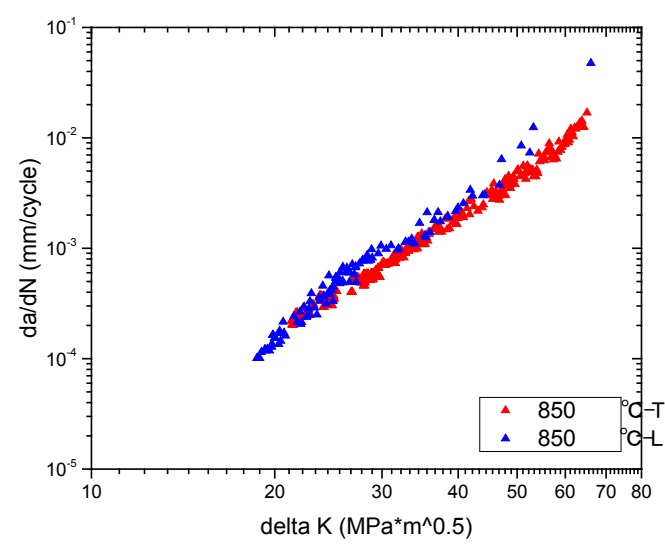

(c) $850^{\circ} \mathrm{C}$

Fig. 8. Inlfluence of orientation on FCG

\subsection{Influence of temperature on FCG rates}

Fig. 9 shows the FCG rates of cracks for orientation L. The temperature dependence is strong at low and medium $\Delta \mathrm{K}$ level. The elevated temperature seems to accelerate the FCG rates 10 times larger than that at room temperature. However, in the higher stress intensity factor, the FCG rate at the room temperature even slightly exceeds that at $760{ }^{\circ} \mathrm{C}$.For high temperature, $90^{\circ} \mathrm{C}$ 's increase can also exhibit obvious difference. As shown in Fig. 9, the curve for $850^{\circ} \mathrm{C}$ is always above the curve of $760^{\circ} \mathrm{C}$ and room temperature. Even in the higher stress intensity level, there is no trend of FCG rates reduction.

For the orientation $\mathrm{T}$, similar temperature independence can be found. This also indicates the weak orientation dependence. The FCG rates of $850^{\circ} \mathrm{C}$ is still the highest than any other temperature through all the $\Delta \mathrm{K}$ level. Meanwhile, at higher $\Delta \mathrm{K}$ level, the FCG rates of room temperature 'caught up' that of $760^{\circ} \mathrm{C}$.

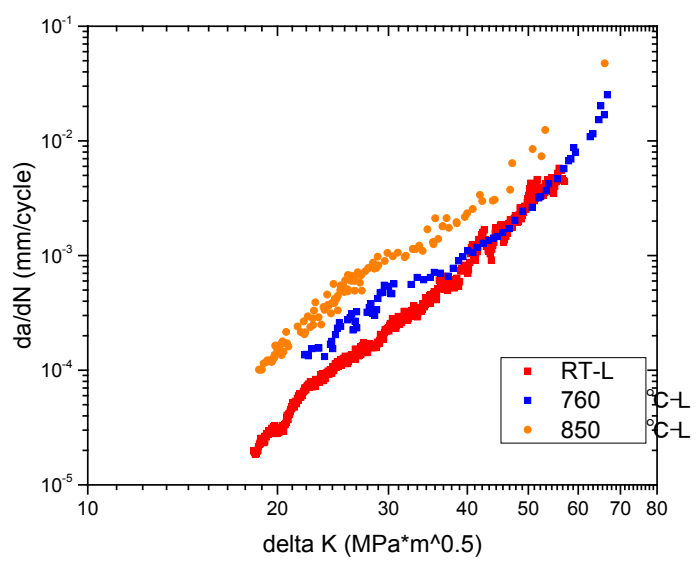

(a) Longitundial orientation

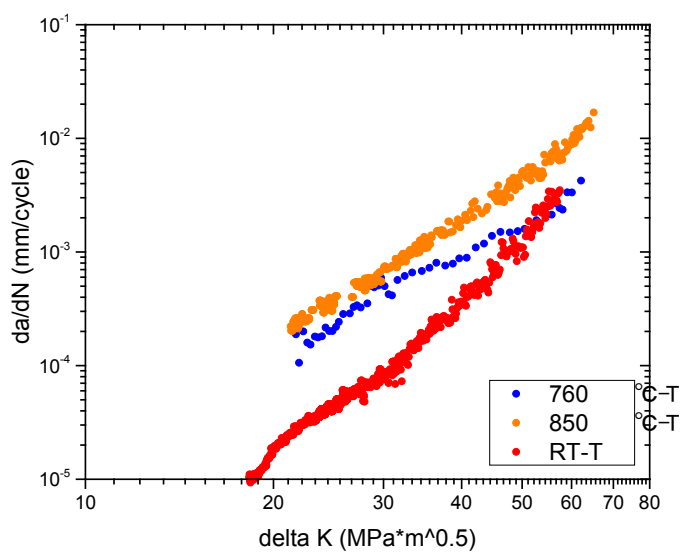

(b) Transeverse orientation

Fig. 9. Influence of temperature on FCG

In conclusion, the increase of temperature can exert strong influence on FCG rates, which speeds up the crack propagation. However, even the room temperature can still have higher FCG rate than $760^{\circ} \mathrm{C}$ in higher $\Delta \mathrm{K}$ level. Generally speaking, high temperature is likely to activate the dislocation motion. And it is also postulated that higher temperature will cause more oxidation, which degraded the material resistance and thus increasing the FCG rates. The reason for the ' collapse' for $760^{\circ} \mathrm{C}$ in higher stress level is likely to be the crack closure effect induced by the oxidation. However, it seems to be paradox for the trend observed at $850^{\circ} \mathrm{C}$. Perhaps the 
reason for accelerating the FCG rates is determined by other factors. For $760^{\circ} \mathrm{C}$, the crack closure plays a more leading role and thus decreasing the FCG rates in higher stress intensity factor level. While for $850^{\circ} \mathrm{C}$, the crack closure effect seems to be weak compared with others, thus the curve of lower temperature fails to exceed 850 ${ }^{\circ} \mathrm{C}$ in higher $\Delta \mathrm{K}$ level.

In the test process, high temperature is also likely to influence the fatigue crack growth threshold. As is shown in Table. 3 two tests of specimens L5 and L6 could last 20503 and 617600 cycles without any signal of propagation. However, under the same test condition, specimens L4 only took 53517 cycles to the length of $25 \mathrm{~mm}$ which was set as the terminal condition. For L5 and L6 specimens, we also examined the CT specimens under optical microscope and no sign of propagation can be found. Therefore, we inferred that the threshold is might larger than that of room temperature. The maximum load for L6 was $0.8 \mathrm{kN}$ larger than that of L4, L5 and other specimens conducted at room temperature before. In the subsequent tests, the temperature was adjusted to $760^{\circ} \mathrm{C}$ with maximum $9.4 \mathrm{kN}$. For tests of L9 and T3, approximately 35000 cycles were consumed before reaching the terminal condition and no 'not propagation' phenomenon were observed with higher maximum loading. It is hypothesized that the crack closure induced by oxidation is more serve than that at room temperature, and thus increase the threshold level. Telesman ${ }^{[14]}$ reported that the fatigue crack growth threshold for a PM nickel based superalloy was influence by temperature and frequency. The increase of temperature will lead to the increase of threshold value. Bouvard ${ }^{[15]}$ and K.S Chan ${ }^{[16]}$ also mentioned that the thickening of oxide layer on the crack lips tends to increase the opening threshold. However, at present we still lack some evidence to confirm that the oxidation in the main cause for this. In addition, it is also hard to explain the test for L4 whose maximum force was $8.6 \mathrm{kN}$. Further efforts should be made to investigate by studying the fractography under SEM.

\section{FCG mode}

All the test specimens were separated into two parts shown in Fig. 10. For specimens at room temperature, all the crack paths were perpendicular to the loading direction, which satisfies the type I crack growth. However, at the elevated temperature, deflections can be observed in all directions at different high temperature. For L specimen under $760^{\circ} \mathrm{C}$, the crack path grew upward with a certain angle, while the counterpart of $\mathrm{T}$ exhibited a 'strange' and downward path. At $850^{\circ} \mathrm{C}$, L and $\mathrm{T}$ specimens travelled in a similar downward path. From the result, it seems that both orientation and temperature could change the fatigue crack growth path. The crack path belongs to the type I-II combined mode. Therefore, the fatigue crack growth path can also to some extent reflect the influence of temperature. The reason for this deflection is likely to be that thermal activated some mechanism and leads to the crack did not travel perpendicularly to the loading direction. And it is also likely to be caused by the barrier of grain in the crack advancing. In other words, the effect of column grain boundary in the FCG process in unneglectable at elevated temperature. More detailed study should be conducted to confirm it.

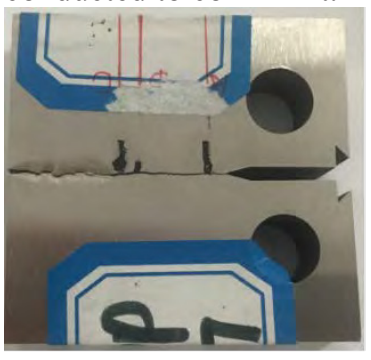

a) RT-L

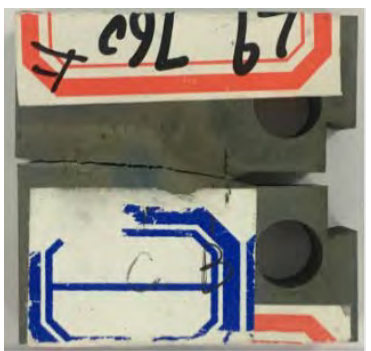

c) $760^{\circ} \mathrm{C}-\mathrm{L}$

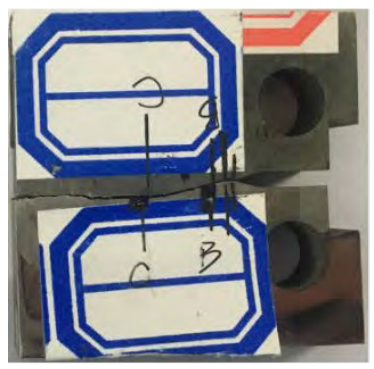

e) $850^{\circ} \mathrm{C}-\mathrm{L}$

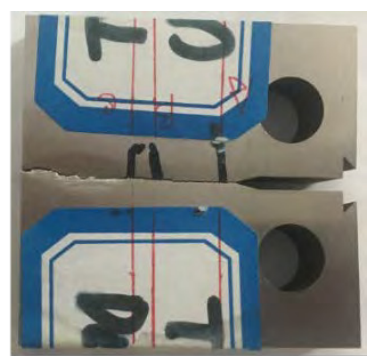

b) RT-T

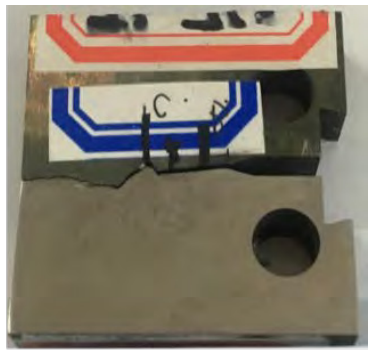

d) $760^{\circ} \mathrm{C}-\mathrm{T}$

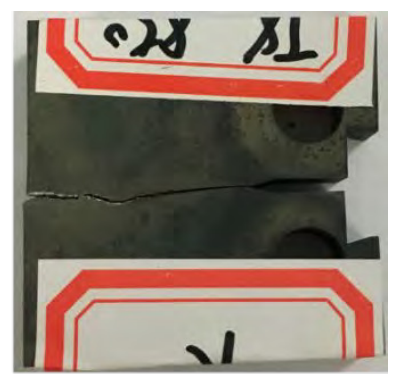

f) $850^{\circ} \mathrm{C}-\mathrm{T}$
Fig. 10. The FCG path of CT

\section{Conclusion}

The influence of temperature and orientation on the fatigue crack growth behavior of directionally solidification superalloys named DZ125 have been investigated in this study. Six CT specimens fall into two orientation (longitudinal and transverse) or three temperature (room temperature, $760^{\circ} \mathrm{C}, 850^{\circ} \mathrm{C}$ ). Relevant conclusions are given below:

1) The orientation influence seems to be most evident at room temperature, and the temperature effect becomes less significant in low and medium $\Delta \mathrm{K}$ level with the increase in temperature. For room temperature, $760^{\circ} \mathrm{C}$ and $850^{\circ} \mathrm{C}$, orientation $\mathrm{L}$ exhibits slightly higher FCG rates than that of $\mathrm{T}$.

2) The increase of temperature accelerated the FCG rates and the difference between the room temperature and elevated temperature is almost an order of magnitude. However, at higher $\Delta \mathrm{K}$ level, the curve of room temperature could exceed that of 760 ${ }^{\circ} \mathrm{C}$ for both orientations, which is mainly contributed 
by the crack closure effect.

3) The fatigue crack growth threshold is also likely to be influenced by the increasing temperature, and it is also hypothesized that oxidation is responsible for this.

4) The fatigue crack growth path is different from room temperature and elevated temperature. Both $\mathrm{L}$ and $\mathrm{T}$ orientation travelled perpendicularly to the loading direction which belongs to the type I crack at room temperature while they both exhibited the combined type I-II crack growth mode at elevated temperature.

\section{References}

1. M.Qiao,C.Zhou, Corros. Sci.,63(10), 239-245 (2012)

2. D.Shi,J.Liu,X.Yang,H.Qi,J.Wang, Mater. Sci. Eng. A, 528(1),233-238 (2010)

3. J.Liang,A.Xing,Z.Wen,Z.Yue, Eng. Failure Anal., 59,326-333 (2015)

4. X.Hu,D.Shi,X.Yang, Mater. Sci. Eng. A, 674,451458 (2016)

5. S.Li,X.Yang,G.Xu,H.Qi,D.Shi, Int. J. Fatigue., 84,91-96 (2016)

6. T.Liang,H.Guo,H.Peng,S.Gong,Chin.J.Aeronaut., 25(5),796-803 (2012)

7. ASTM International. Standard test method for measurement of fatigue crack growth rates E647-15 (2015)

8. J.Renart,J.Vicens,S.Budhe,A.RodriguezBellido,J.comas, Int. J. Fatigue., 82, 634-642 (2016)

9. D.Ewest,P.Almroth,B.Sjodin,K.Simonsson,D.Leider mark, Int. J. Fatigue., 92, 61-70 (2016)

10. B.Pan, Acta Opt. Sin., 31(2), (2011)

11. China aviation material manual editorial board, China aeronautical material manual second volume superalloy casting high temperature alloy (2002)

12. X.He,Y.Zhang,H.Shi,J.Gu,C.Li, Mater. Sci. Eng. A, 618,153-160 (2014)

13. K.Yoon,T.Park,A.Saxena, Stren. Fract. \& Complex., 4(1) (2005)

14. J.Telesman,T.Smith,T.Gabb,A.Ring, Mater. Sci. Eng. A,708 (2017)

15. J.Bouvard,F.Gallerneau,P.Paulmier,J.Chaboche, Int. J. Fatigue., 38(5), 130-143 (2012)

16. K.Chan,High.Temp.Technol.,33(4-5),425-438 (2016) 